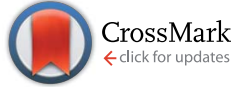

Cite this: J. Mater. Chem. C, 2015, 3, 2358

Received 22nd December 2014 Accepted 13th January 2015

DOI: $10.1039 / c 4 t c 02931 c$

www.rsc.org/MaterialsC

\section{H-1,2,6-Thiadiazin-4-one-containing small molecule donors and additive effects on their performance in solution-processed organic solar cells $\dagger$}

\author{
Felix Hermerschmidt, ${ }^{* a}$ Andreas S. Kalogirou, ${ }^{b}$ Jie Min, ${ }^{c}$ Georgia A. Zissimou, ${ }^{b}$ \\ Sachetan M. Tuladhar, ${ }^{d}$ Tayebeh Ameri, ${ }^{c}$ Hendrik Faber, ${ }^{d}$ Grigorios Itskos, ${ }^{e}$ \\ Stelios A. Choulis, ${ }^{a}$ Thomas D. Anthopoulos, ${ }^{d}$ Donal D. C. Bradley, ${ }^{d}$ Jenny Nelson, ${ }^{* d}$ \\ Christoph J. Brabec ${ }^{\star c}$ and Panayiotis A. Koutentis ${ }^{\star b}$
}

\begin{abstract}
The optical, electrochemical, morphological and transport properties of a series of thiadiazinone (acceptor) and (thienyl)carbazoles (donor) containing $\pi$-extended donor-acceptor-donors (D-A-D) are presented. Systematic variations in the number of the thienyl units, the choice of branched or straight alkyl side chains and the use of a processing additive demonstrate their use as electron donors in bulk heterojunction solar cells blended with fullerene acceptors. The best power conversion efficiency (PCE) of $2.7 \%$ is achieved by adding to the D-A-D 3 : fullerene blend a polydimethylsiloxane (PDMS) additive, that improves the morphology and doubles the hole mobility within the $D-A-D$ : fullerene blend.
\end{abstract}

\section{Introduction}

Incident sunlight falling on Earth in 1 hour is sufficient to satisfy the average yearly human energy consumption; ${ }^{1}$ not surprisingly, the interest in solar energy has grown rapidly. Organic photovoltaics (OPVs), which are free of expensive rare earth metals, can provide a low-cost, solution-processable and environmentally friendly alternative to generate electricity.

Bulk-heterojunction (BHJ) OPV devices, which use a bulk mixture of an electron donating and an electron accepting unit, to provide a flow of electrons and holes to the relevant electrodes, have reached certified power conversion efficiencies (PCEs) for single-junction devices $>9 \%,{ }^{2,3}$ and $>10 \%$ for tandem cells. $^{4,5}$ These devices typically contain an active layer comprising a conjugated polymer as the electron donating unit such as PTB7, PCDTBT, Si-PCPDTBT or P3HT and a soluble

\footnotetext{
${ }^{a}$ Molecular Electronics and Photonics Research Unit, Department of Mechanical Engineering and Materials Science and Engineering, Cyprus University of Technology, 3041 Limassol, Cyprus

${ }^{b}$ Department of Chemistry, University of Cyprus, 1678 Nicosia, Cyprus

'Institute of Materials for Electronics and Energy Technology, Friedrich-Alexander University Erlangen-Nuremberg, 91054 Erlangen, Germany

${ }^{d}$ Department of Physics, Imperial College London, London SW7 2AZ, UK

${ }^{e}$ Experimental Condensed Matter Physics Laboratory, Department of Physics, University of Cyprus, 1678 Nicosia, Cyprus

$\dagger$ Electronic supplementary information (ESI) available: Synthesis and structural characterisation of materials, ${ }^{1} \mathrm{H}$ and ${ }^{13} \mathrm{C}$ NMR spectra of D-A-D molecules, electrochemistry, cyclic voltammograms, fabrication and characterisation of organic solar cells. See DOI: 10.1039/c4tc02931c
}

fullerene as electron acceptor such as PC60BM, PC70BM or ICBA $^{2,6-8}$

Small molecules have recently been used as donor and acceptor components in $\mathrm{BHJ}^{-O P V s}{ }^{9}$ and device efficiencies of 7$9 \%$ have been achieved for single-junction solar cells, ${ }^{\mathbf{1 0}-15}$ while a $10.1 \%$ PCE has been achieved for a solution-based small molecule tandem cell. ${ }^{12}$

Advantages of small molecules include well-defined structures and characterisability, higher manufacturing yields, facile purification techniques, ${ }^{\mathbf{1 6}}$ and their reproducible, less complex syntheses. ${ }^{17}$ Devices employing solution-processed small molecules as both donor and acceptor components gave device efficiencies of $\sim 3 \%,{ }^{18}$ which is similar to the average device performance of the widely studied and extensively optimized polymer : fullerene P3HT : PC60BM system. ${ }^{19}$ As a result of this progress, a wide variety of new small molecules for solutionprocessed organic photovoltaics are being prepared, ${ }^{\mathbf{2 0 - 2 4}}$ including efficient donor-acceptor-donor (D-A-D) systems. ${ }^{25}$

A recent electrochemical study of non-oxidised $4 H-1,2,6$ thiadiazines indicated electron affinities (LUMO energy values) of -3.25 to $-3.66 \mathrm{eV}$ with reversible oxidations and reductions. ${ }^{26}$ As such, these heterocycles are promising as acceptor building blocks for D-A-D small molecule donors and for polymerization with various prominent comonomers to produce solar harvesting polymers. The presence of an appropriate electron-deficient $4 H-1,2,6$-thiadiazine in the donor molecule can be used to control the energy level of the LUMO while that of the HOMO can be regulated by the incorporation of electron-rich substituents such as thiophene and carbazole. 
Interestingly, while non-oxidised $4 H-1,2,6$-thiadiazines are rare heterocycles, several analogues have useful medicina $\mathrm{l}^{27}$ and agrochemical $^{28}$ properties. In the material sciences both Woodward ${ }^{29}$ and Rees $^{30-32}$ proposed potentially stable poly $\left(4 H^{-}\right.$ 1,2,6-thiadiazine) analogues of the inorganic superconductor poly(sulfur nitride). Furthermore, fused analogues were studied as examples of "extreme quinoids" that have ambiguous aromatic character, ${ }^{33}$ while others displayed unusual liquid crystalline properties or behaved as near-infrared dyes. ${ }^{34,35}$

Herein, we show that $4 H-1,2,6$-thiadiazinone-containing small molecule donors can be used in BHJ OPVs. Systematic variations in the structures of the materials and use of a processing additive during device fabrication led to power conversion efficiencies of $2.7 \%$.

\section{Results and discussion}

\subsection{Synthesis of small molecule donors 2-8}

A range of thiadiazinone (acceptor) and (thienyl)carbazoles (donor) containing $\pi$-extended donor-acceptor-donor (D-A-D) small molecules (2-8) were prepared and studied as light harvesting p-type semiconductors (Scheme 1). The synthesis of the D-A-D small molecules started from 3,5-dichloro-4H-1,2,6thiadiazin-4-one (1), that can be readily prepared in two steps from dichloromalononitrile and $\mathrm{SCl}_{2}$ in multigram quantities, ${ }^{36}$ and is a versatile building block that can participate in a range of palladium catalysed $\mathrm{C}-\mathrm{C}$ coupling reactions such as Stille and Suzuki-Miyaura couplings to give various 3,5-di(het)aryl substituted systems. ${ }^{37,38}$ The synthesis and their characterisation appear in the ESI. $\dagger$ All the compounds were readily soluble in tetrahydrofuran (THF) and dichloromethane (DCM).

\subsection{Photophysical properties}

UV-vis absorption spectra of the D-A-Ds 2-8 for both solutions (in DCM) and thin films (doctor-bladed from PhCl) (Fig. 1), show that the latter spectra are red-shifted and broader
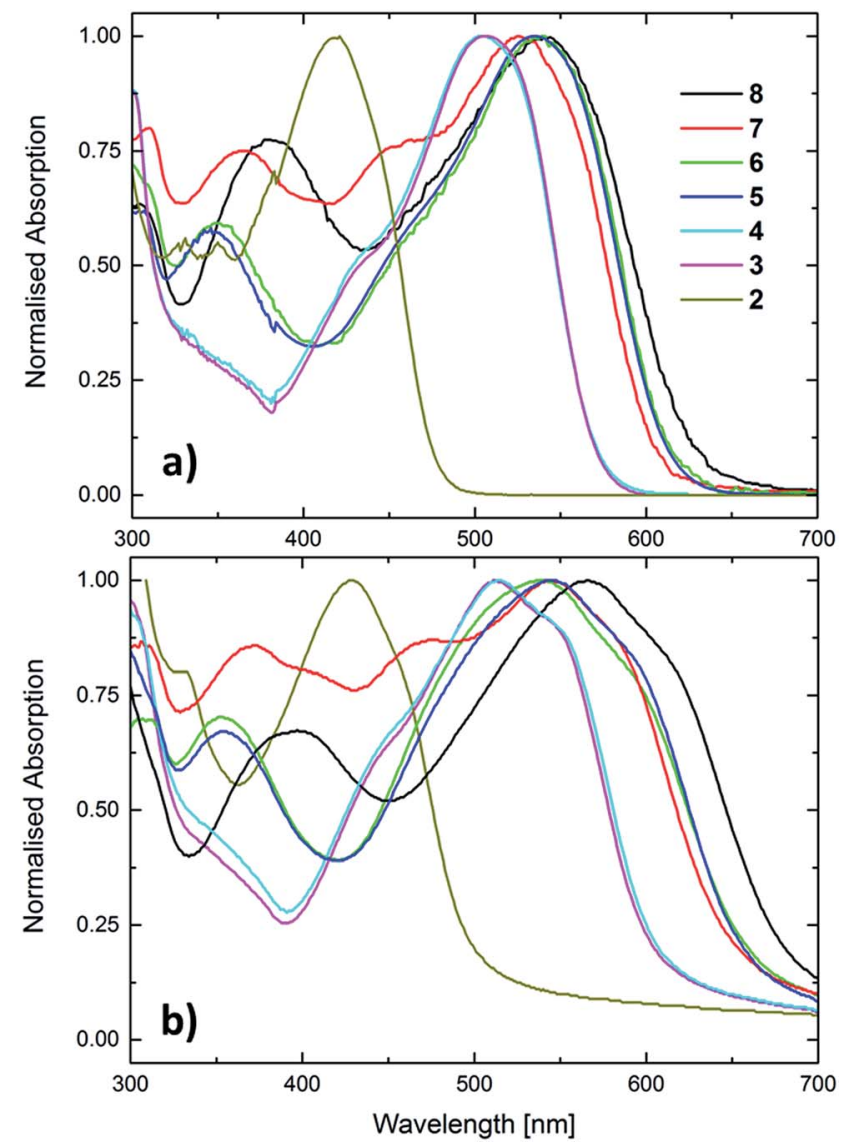

Fig. 1 Comparison of all the normalised UV-vis spectra of the $\mathrm{D}-\mathrm{A}-\mathrm{Ds}$ 2-8 in (a) solution (DCM) and (b) film (doctor-bladed from $\mathrm{PhCl}$ ).

compared to the former. This can be attributed to stronger electronic and structural interactions that exist in the solid state. $^{39}$

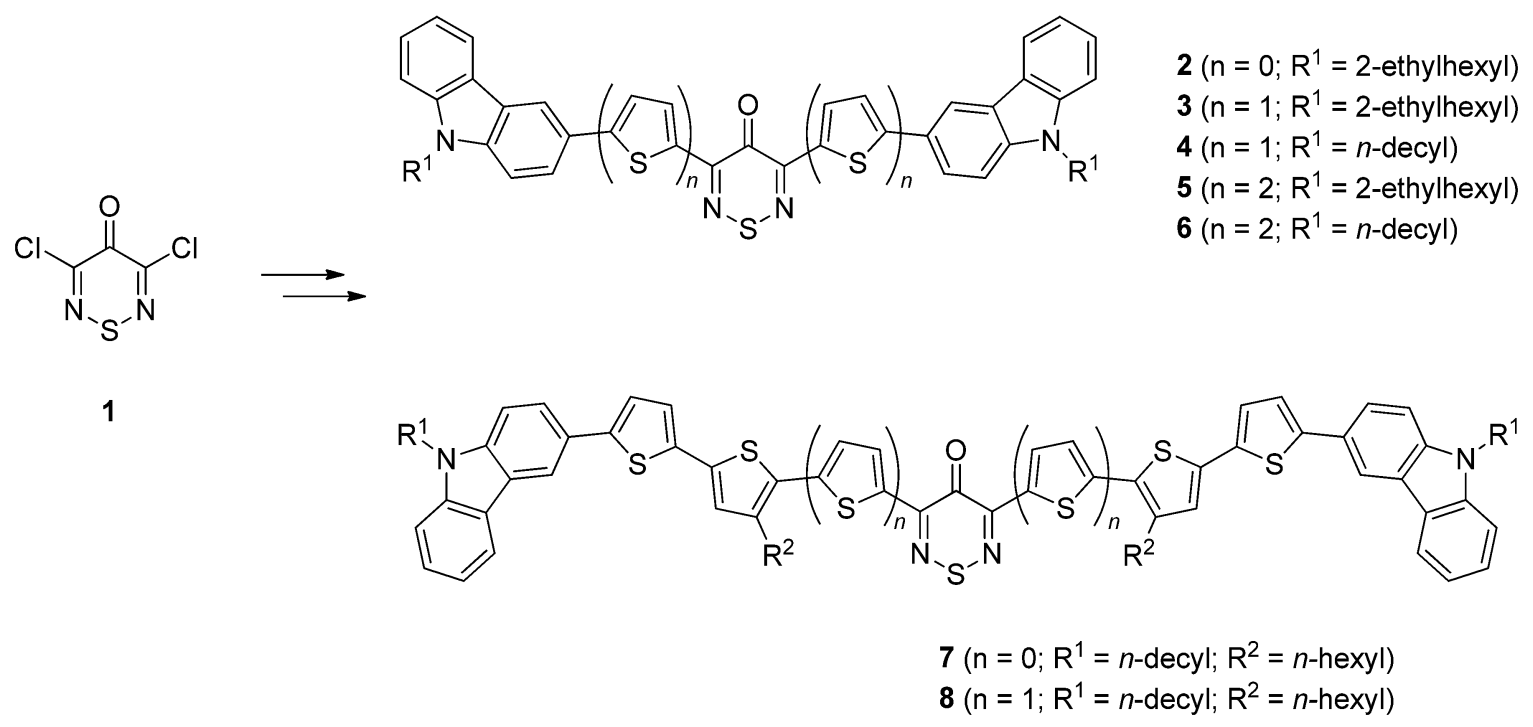

Scheme 1 Chemical structure of small molecule D-A-Ds 2-8 prepared from 3,5-dichloro-4H-1,2,6-thiadiazin-4-one (1). 
Table 1 Overview of all optical and electrochemical characteristics of the studied D-A-Ds in solution and in the solid state

\begin{tabular}{|c|c|c|c|c|c|c|c|c|c|}
\hline D-A-D & $\begin{array}{l}\lambda_{\max } \\
\text { sol. (nm) }\end{array}$ & $\begin{array}{l}\lambda_{\max } \\
\text { film }(\mathrm{nm})\end{array}$ & $\begin{array}{l}E_{\mathrm{g}}^{\mathrm{opt}} \\
\text { sol. }(\mathrm{eV})\end{array}$ & $\begin{array}{l}E_{\mathrm{g}}^{\mathrm{opt}} \\
\text { film }(\mathrm{eV})\end{array}$ & $\begin{array}{l}E^{\mathrm{ox}} \\
(\mathrm{V})\end{array}$ & $\begin{array}{l}E_{\text {HOMо }} \\
(\mathrm{eV})\end{array}$ & $\begin{array}{l}E^{\mathrm{red}} \\
(\mathrm{V})\end{array}$ & $\begin{array}{l}E_{\text {LUMO }} \\
(\mathrm{eV})\end{array}$ & $\begin{array}{l}E_{\mathrm{g}}^{\text {echem }} \\
(\mathrm{eV}) \\
\end{array}$ \\
\hline 2 & 414 & 428 & 2.61 & 2.49 & 0.82 & -5.92 & -1.72 & -3.38 & 2.56 \\
\hline 4 & 501 & 514 & 2.12 & 2.06 & 0.44 & -5.54 & -1.58 & -3.52 & 2.02 \\
\hline 5 & 534 & 545 & 2.04 & 1.88 & 0.32 & -5.42 & -1.51 & -3.59 & 1.83 \\
\hline 6 & 535 & 539 & 2.02 & 1.87 & 0.30 & -5.40 & -1.54 & -3.56 & 1.84 \\
\hline
\end{tabular}

The least-conjugated 3,5-di(carbazol-3-yl)thiadiazinone 2 shows an absorption that corresponds to an optical band gap of $2.61 \mathrm{eV}$, while the most conjugated, 3,5-di(terthienylcarbazol-yl) thiadiazinone $\mathbf{8}$, shows an absorption that corresponds to the smallest optical band gap in the series $(1.99 \mathrm{eV})$. Thiadiazinones 3-7 show absorptions that correspond to optical band gaps $\left(E_{\mathrm{g}}^{\mathrm{opt}}\right)$ in the range of 2.17-2.02 eV (Table 1).

The absorption profiles depend on the number of thienyls present in the D-A-Ds. The longest wavelength absorption maxima in the solid state ranks accordingly: 8 (terthienyl) $>\mathbf{7 - 5}$ (bithienyl) $>4,3$ (thienyl) $\gg 2$ (no thienyl). In solution, the 2,2'bithienyl substituted D-A-Ds 5 (534 nm) and 6 (535 nm) have similar absorption maxima, while the 2,2'-bithienyl substituted D-A-D $7(522 \mathrm{~nm})$ that hosts $n$-hexyl side chains on the bithienyls, has a slightly shorter wavelength maximum, which we attribute to increased steric constraints emposed by the $n$ hexyl groups on D-A-D 7, that interfere with the planarity.

D-A-D 7, however, shows a $22 \mathrm{~nm}$ red shift of the absorption maximum between solution and solid state, to give similar absorption maxima to the solid state films of the 2,2'-bithienyls analogues 5 and 6 (Table 1, 544 vs. 545 and 539 nm, respectively); in the solid state, $\pi-\pi$ and lipophilic interactions must enable a structural reorganisation of D-A-D 7 to overcome these steric constraints. A similar magnitude red shift can be expected for the D-A-D 8 that has the same number of alkyl side chains as D-A-D 7 but this was not observed: presumably, D-A-D 8, which is significantly larger, requires more energy to reorganize in the solid state, although the position of the $n$-hexyl substituted thienyl also differs from that of D-A-D 7, and this can also play a role. The additional $n$-hexyl side chains on the D-A-D 7 also influence the overall absorption range, resulting in broad absorption between 300-600 nm, which includes the absorption regime of PC70BM (350-500 nm), ${ }^{40}$ this broadening effect was also not observed with D-A-D 8.

The influence of the carbazole $N$-alkyl side chain ( $n$-decyl or 2-ethylhexyl) is negligible: $\mathrm{D}-\mathrm{A}-\mathrm{D}$ pairs $3 / \mathbf{4}$ and $\mathbf{5 / 6}$ gave similar absorptions. This cannot be said for the $n$-hexyl side chains on the interior thienyls, which, in at least one example (D-A-D 8), affect the absorption maximum in solution.

Photoluminescence (PL) spectra of the pristine D-A-Ds show a single broad emission, Stoke-shifted by 150-200 meV from the respective molecule's absorption peak (Fig. 2). In contrast, the emissions from the blends with PC70BM are quenched; only traces of the D-A-Ds' emission together with a small emission from PC70BM at $\sim 720 \mathrm{~nm}$ (ref. 41 ) were observed.

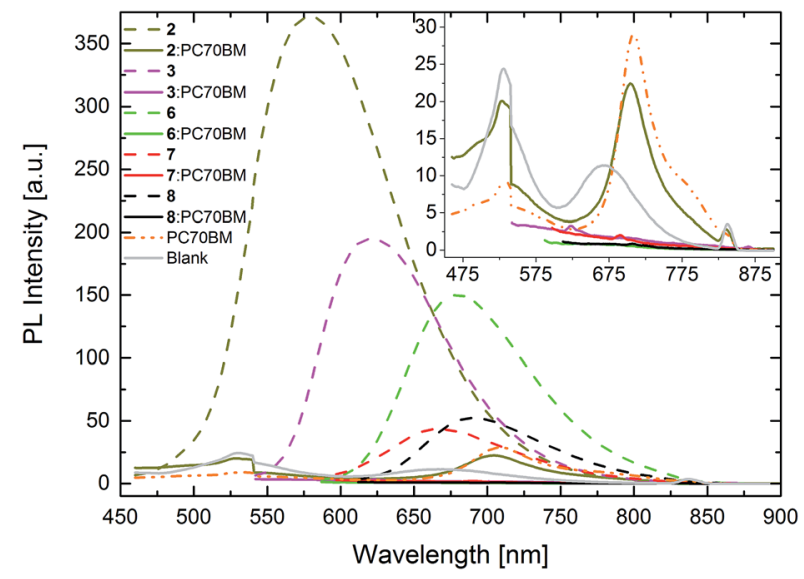

Fig. 2 Photoluminescence measurements of pristine small molecule D-A-Ds 2-8 and blends with PC70BM. The inset shows an enlarged area of the blend $\mathrm{PL}$.

The PL quenching can be quantified by a quenching ratio, ${ }^{42}$ yielding values $>90 \%$ for each $\mathrm{D}-\mathrm{A}-\mathrm{D}$ blend (Fig. 2 inset). These high quenching ratios attest to efficient exciton dissociation and charge separation at the heterointerfaces of the D-A-D : PC70BM blends. ${ }^{43}$

\subsection{Electrochemical properties}

Cyclic voltammetry (CV) of the D-A-Ds show that the 3,5-di(carbazolyl)thiadiazinone 2 has the lowest HOMO energy level $(5.92 \mathrm{eV})$, as well as the largest electrochemical band gap $\left(E_{\mathrm{g}}^{\text {echem }} 2.56 \mathrm{eV}\right)$, leading to poor hole transport between acceptor and donor HOMOs. The inclusion of one or two thienyls between the central thiadiazinone and the peripheral carbazoles significantly raised the $\operatorname{HOMO}(-5.54$ to $-5.40 \mathrm{eV})$ but only marginally raised the LUMO $(-3.59$ to $-3.52 \mathrm{eV})$ energy levels, leading to a net reduction of the $E_{\mathrm{g}}^{\text {echem }}$ (Table 1).

The $E_{\mathrm{g}}^{\text {echem }}$ values of D-A-Ds 2-8 (2.56-1.74 eV) were in close agreement with the optical band gaps calculated from the onset of the UV-vis absorption. Modifying the $N$-alkyl chain on the carbazole from a 2-ethylhexyl to a $n$-decyl chain did not affect the electrochemical characteristics of the D-A-Ds; the thiadiazinone pairs $3 / 4$ and 5/6 gave similar values of HOMO/LUMO energy levels as well as electrochemical band gaps. A slightly larger deviation was observed with analogue 7 and the pair 5/6 owing to the incorporation of the $n$-hexyl side chains on the two 
thienyls. The 3,5-di(terthienylcarbazolyl)-thiadiazinone 8, owing to an extended $\pi$ system and inclusion of more electronrich terthienyls, has a higher HOMO energy level $(-5.34 \mathrm{eV})$ while its LUMO energy $(-3.60 \mathrm{eV})$ remains comparable with the other thiadiazinones, giving a more desirable $E_{\mathrm{g}}^{\text {echem }}$ of $1.74 \mathrm{eV}$ (Table 1).

On moving from D-A-D 2-8, cyclic voltammetry shows a small but gradual increase in their HOMO energies while their LUMO energies, with the exception of 2 , show only minor changes (Fig. 3).

As will be described below, this shift in energy leads to a decrease in the measured values of $V_{\text {OC }}$ from 1.00 to $0.74 \mathrm{~V}$ when moving from D-A-D 3-8 as the value of the $V_{\mathrm{OC}}$ is proportional to the difference between HOMO energy level of the donor material and the LUMO energy level of the acceptor compound. ${ }^{44}$

\subsection{Photovoltaic properties}

OPV-BHJ devices based on an optimal blend ratio of D-A-D : PC70BM $1: 2 \mathrm{wt} \%$, showed PCE with high $V_{\mathrm{OC}}$ values ( 1 V) (Table 2, Fig. 4).

The $V_{\mathrm{OC}}$ values reduce approximately with the reduction in donor HOMO/acceptor LUMO energy level offset (from CV), which can be regarded as proportional to $V_{\mathrm{OC}} \cdot{ }^{\mathbf{4 4 , 4 5}}$ This has been shown in the empirical equation by Scharber et al., ${ }^{\mathbf{4 6}}$ relating the band gap with $V_{\mathrm{OC}}$ :

$$
V_{\mathrm{OC}}=\frac{1}{e}\left(E_{\mathrm{HOMO}}^{\mathrm{Donor}}-E_{\mathrm{LUMO}}^{\text {Acceptor }}\right)-0.3 V
$$

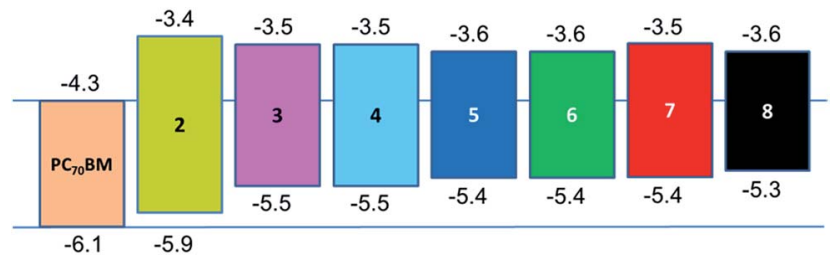

Fig. 3 Experimentally obtained $\mathrm{HOMO}$ and LUMO energy level values (rounded to nearest $0.1 \mathrm{eV}$ ) of the donor small molecule compounds in relation to the acceptor fullerene PC70BM.

Table 2 Photovoltaic properties of D-A-D: PC70BM (1:2, wt\%) devices, under the illumination of AM 1.5, $100 \mathrm{~mW} \mathrm{~cm}^{-2}$

\begin{tabular}{lllll}
\hline $\mathrm{D}-\mathrm{A}-\mathrm{D}: \mathrm{PC}_{70} \mathrm{BM}$ & $V_{\mathrm{OC}}(\mathrm{V})$ & $J_{\mathrm{SC}}\left(\mathrm{mA} \mathrm{cm}^{-2}\right)$ & $\mathrm{FF}(\%)$ & PCE $(\%)$ \\
\hline $\mathbf{2}$ & 0.70 & 0.06 & 24.26 & 0.01 \\
$\mathbf{3}$ & 1.00 & 6.47 & 32.30 & 2.09 \\
$3^{a}$ & 1.00 & 8.20 & 33.08 & 2.71 \\
$\mathbf{4}$ & 0.95 & 6.07 & 33.10 & 1.91 \\
$\mathbf{5}$ & 0.90 & 6.82 & 36.43 & 2.23 \\
$\mathbf{6}$ & 0.90 & 7.50 & 40.35 & 2.52 \\
7 & 0.90 & 4.24 & 31.51 & 1.20 \\
$\mathbf{8}$ & 0.85 & 4.35 & 31.50 & 1.17
\end{tabular}

${ }^{a}$ With PDMS, $0.1 \mathrm{mg} \mathrm{mL}^{-1}$.
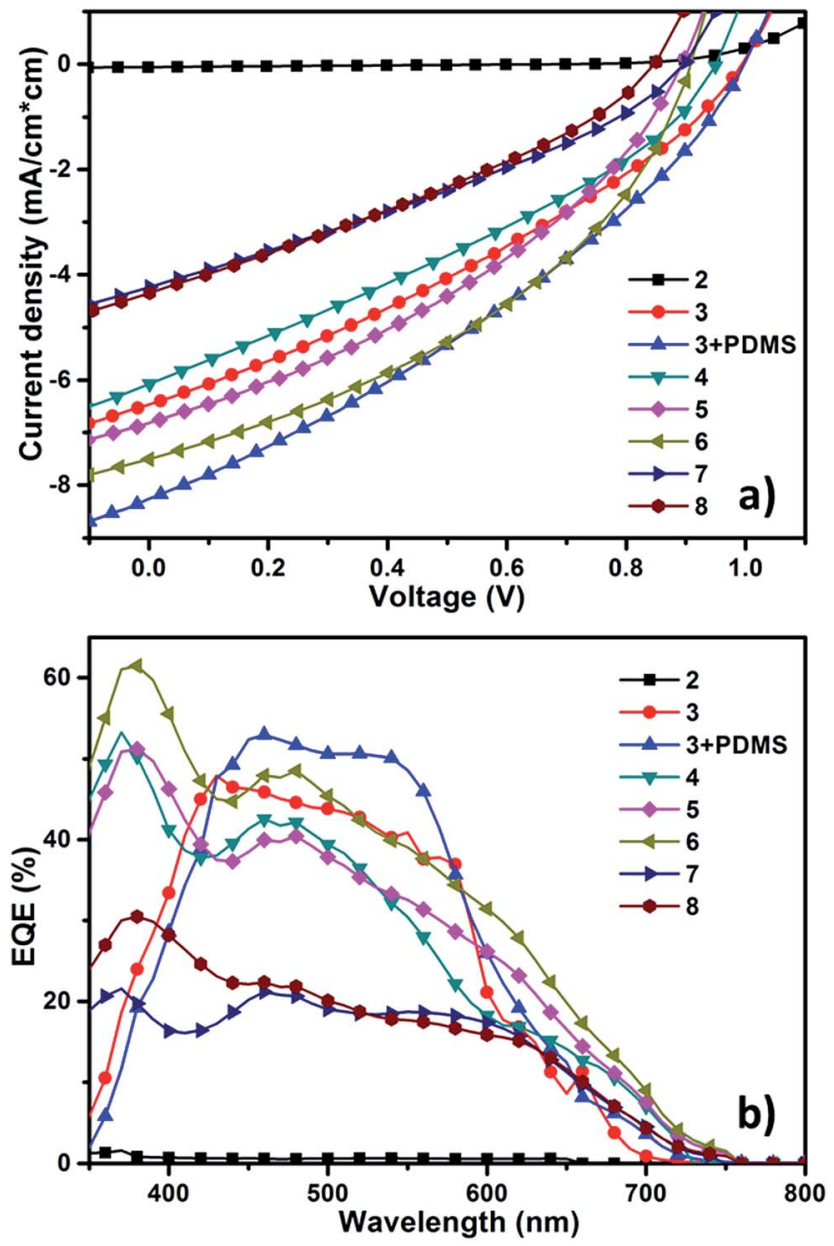

Fig. 4 Current density-voltage $(J-V)$ curves (a) and EQE spectra (b) of solar cells based on D-A-D : PC70BM (1:2 wt\%), respectively, under the illumination of $A M 1.5,100 \mathrm{~mW} \mathrm{~cm}^{-2}$.

with $e$ being the charge of an electron and $E$ the energy level of the donor HOMO and acceptor LUMO, respectively.

As expected from the CV data, the D-A-D 2 does not yield useful photovoltaic performance. While the LUMO/LUMO donor/acceptor offset is not unfavourable since it approximates the offset for the well-studied P3HT : PCBM system, ${ }^{\mathbf{4 0}}$ the lack of a favourable HOMO/HOMO offset between donor and acceptor (see Fig. 3) presumably leads to an unfavourable hole transfer. The $V_{\text {OC }}$ values of the devices based on the D-A-Ds 3-8, however, do agree with the HOMO energy levels of the relevant molecules.

The highest performing D-A-Ds 3-5 also have the highest produced $J_{\text {SC }}$ (Table 2 ), and a trend exists between measured $J_{\text {SC }}$ and device performance, which also holds true for the obtained external quantum efficiency (EQE).

The fill factors (FF) obtained for the series of D-A-D : PC70BM blends also roughly show this same trend, however the low values limit the overall device performance obtained. As will be shown below, this can primarily be attributed to the charge carrier mobility and morphology within the system. 
To improve the device performance, an additive was introduced into the D-A-D : PC70BM active blend. This approach has been successfully applied in a variety of polymer and small molecule-based systems. ${ }^{47-51}$ Adding a small amount of polydimethylsiloxane (PDMS; $2000 \mathrm{~g} \mathrm{~mol}^{-1}$ ) to the D-A-D 3 : PC70BM blend led to an increase $(\sim 30 \%)$ in $J_{\mathrm{SC}}$ and PCE. However, this increase was not seen with other blends; similar behaviour occurs in other small molecule material systems. ${ }^{52}$ Tentative reasons for the improvement in the D-A-D 3 : PC70BM blend are given below.

To understand the reasons behind the trends in PCE, $J_{\mathrm{SC}}$ and EQE in our series of D-A-D : PC70BM systems, we performed morphological and charge transport characterisations (see below).

\subsection{Morphology}

The D-A-D : PC70BM blends were investigated using atomic force microscopy (AFM, see Fig. 5) to probe the surface topography and in general, showed similar roughness parameters (rms 1-5 nm). Films of blends containing D-A-Ds 4, 6-8, which host only straight alkyl side chains, showed similar but distinctly different topologies than those containing D-A-Ds 3, 3 + PDMS and 5, which all host branched alkyl side chains; blends of the latter had smaller feature sizes than their straight alkyl chain analogues. This was particularly clear when comparing the AFM images of $\mathrm{D}-\mathrm{A}-\mathrm{D}$ pairs $\mathbf{3} / \mathbf{4}$ as well as $\mathbf{5 / 6}$, which differ only by their side chains. As such, the nature of the side chains influences the structural blending between the D-A-Ds and PC70BM. No film forming correlation was noted regarding the number of thienyls present in the D-A-Ds.

The improvement in morphology on adding PDMS has been attributed to the smaller feature sizes visible in AFM images, resulting in higher $J_{\mathrm{SC}}$ values. ${ }^{48}$ In our case, adding PDMS to the D-A-D 3 : PC70BM led to similar small feature sizes but not as well contrasted as noted previously. ${ }^{48}$ Since the D-A-D 3 + PDMS blend showed an increase in $J_{\mathrm{SC}}$ and device performance compared to the absence of additive (Table 2), we investigated the charge carrier mobility in pristine materials and blends (see below) to identify if transport related phenomena were the reason for the increase in device performance.

\subsection{Charge carrier mobility}

For efficient photovoltaic performance values, good transport properties within the active layer are important. Hole mobilities $\geq 10^{-3} \mathrm{~cm}^{2} \mathrm{~V}^{-1} \mathrm{~s}^{-1}$ are desired to avoid recombination of separated carriers before they reach their respective electrode.$^{53}$ To provide insight into the hole mobilities of the series of D-A-Ds, hole-only space-charge limited current (SCLC) devices were prepared (Table 3, Fig. 6).

The hole mobilities obtained through SCLC measurements correlate well with the respective small molecule blend OPV performance, indicating that the hole mobility is responsible for the differences seen in the device performance. The same trend can be seen in the $J_{\mathrm{sc}}$ values obtained in the photovoltaic devices (Table 2), confirming the finding
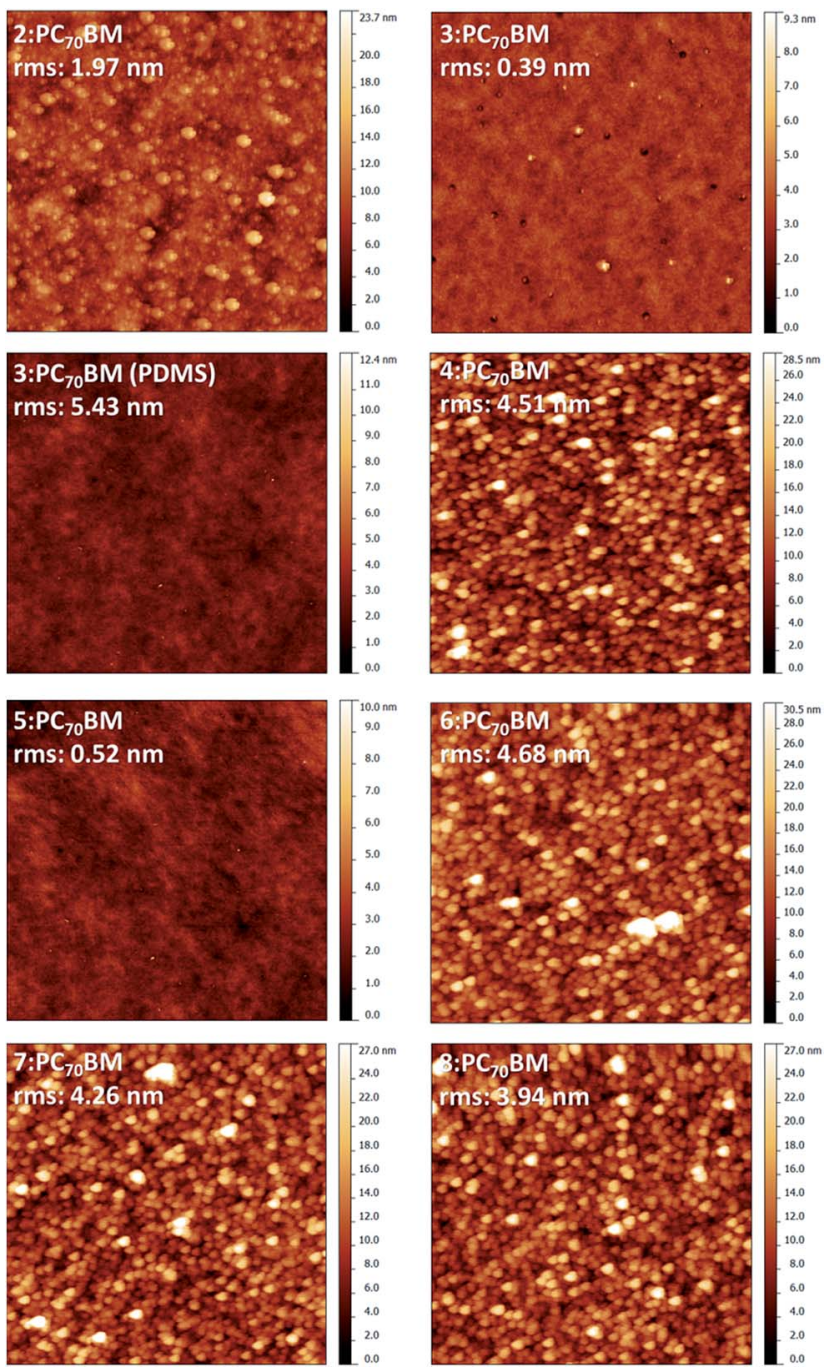

Fig. 5 Atomic force microscopy images showing D-A-D : PC70BM blends ( $1: 2$ wt\%). All image sizes are $5 \times 5 \mu \mathrm{m}$ rms stands for root mean square and indicates the roughness of the surface.

Table 3 Hole mobilities determined from the SCLC measurements

\begin{tabular}{lll}
\hline D-A-D & $\begin{array}{l}\text { Hole mobility } \\
\left(\mu_{\mathrm{h}}\right)\left(\mathrm{cm}^{2} \mathrm{~V}^{-1} \mathrm{~s}^{-1}\right)\end{array}$ & $\begin{array}{l}\text { Blend based hole } \\
\text { mobility }^{b}\left(\mu_{\mathrm{h}}\right) \\
\left(\mathrm{cm}^{2} \mathrm{~V}^{-1} \mathrm{~s}^{-1}\right)\end{array}$ \\
\hline $\mathbf{2}$ & $3.34 \times 10^{-6}$ & $8.23 \times 10^{-7}$ \\
3 & $1.49 \times 10^{-4}$ & $4.55 \times 10^{-5}$ \\
$3^{a}$ & & $9.40 \times 10^{-5}$ \\
$\mathbf{4}$ & $9.03 \times 10^{-6}$ & $6.24 \times 10^{-6}$ \\
$\mathbf{5}$ & $2.65 \times 10^{-5}$ & $2.24 \times 10^{-5}$ \\
$\mathbf{6}$ & $1.08 \times 10^{-4}$ & $8.08 \times 10^{-5}$ \\
7 & $5.62 \times 10^{-6}$ & $2.82 \times 10^{-6}$ \\
$\mathbf{8}$ & $4.49 \times 10^{-6}$ & $3.36 \times 10^{-6}$
\end{tabular}

${ }^{a}$ Blended film based on D-A-D 6 : PC70BM with PDMS, $0.1 \mathrm{mg} \mathrm{mL}^{-1}$. ${ }^{b}$ The reported mobility data are average values of each pristine and blended films for six diodes.

that the carriers in the blends with the higher mobilities can reach the electrodes before recombining and therefore contribute to the overall obtained current. 

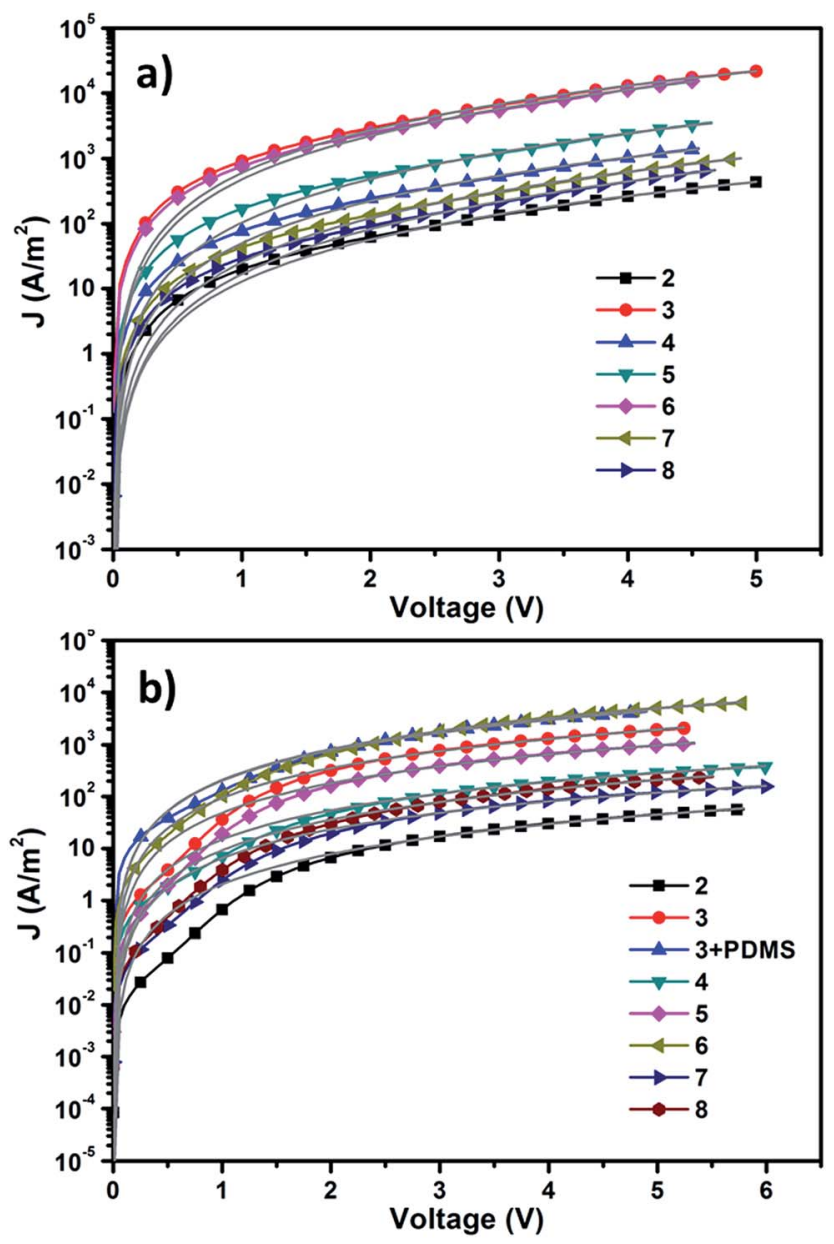

Fig. 6 Hole-only mobilities of pristine (a) and blended films (b) with PC70BM as acceptor.

This is particularly the case for the D-A-D 3 : PC70BM : PDMS blend film, which shows a doubling in hole mobility upon inclusion of the additive (Table 3 ) as opposed to without. On the other hand, the poor hole mobility seen in the D-A-D 2 : PC70BM blend film supports the observations made from electrochemistry, where there is no favourable driving force to convey holes to the relevant electrode.

Having ascertained this trend in hole-mobility with device performance in SCLC-based devices, representative field effect transistors were fabricated to confirm the SCLC findings and also to examine electron mobilities under lateral transport conditions (Table 4).
The representative FET measurements show roughly the same trend in hole mobilities with device performance, but average one order of magnitude lower values than those obtained using SCLC (Table 3). When comparing pristine $\mathrm{D}-\mathrm{A}-\mathrm{D} 3$ and $\mathrm{D}-\mathrm{A}-\mathrm{D} 3+$ PDMS, the hole mobility is largely unaffected. In the D A D 3 : PC70BM blend, the hole mobility is reduced, indicating inhibition of hole mobility by the fullerene. However, the addition of PDMS to the D-A-D 3 : PC70BM blend leads to an approximate doubling in hole mobility. This same trend is also observed in the SCLC mobility values obtained, but at an order of magnitude higher. This may be attributed to the fact that lateral and not vertical transport characteristics are measured in FETs.

Overall, the increase in hole mobility and relative stability of electron mobility upon addition of an additive are consistent with other observations, specifically diiodooctane ${ }^{50}$ and 1chloronaphthalene, ${ }^{51}$ both of which behave similarly to PDMS. ${ }^{54}$ The addition of PDMS to the D-A-D : PC70BM blends of 2 and 6 did not lead to significant hole or electron mobility increases, but did lead to the significant increase in hole mobility for the D-A-D 3 : PC70BM blend above.

The morphology of the D-A-D 3 : PC70BM blend is therefore not optimum and addition of PC70BM disturbs the hole mobility within the D-A-D 3 : PC70BM blend. The addition of PDMS then, has a beneficial effect on the D-A-D 3:PC70BM blend morphology, leading to the observed increases in hole only mobility.

\section{Conclusions}

A series of small molecule donors containing $4 H-1,2,6$-thiadiazin4-one were studied as active layer materials in organic solar cells. High $V_{\mathrm{OC}}$ values were observed but the $J_{\mathrm{SC}}$ and $\mathrm{FF}$ device performance parameters limited the PCE values. Adding PDMS to the D-A-D 3 : PC70BM blend improved the morphology, which led to a doubling of the hole mobility and gave the most efficient PCE $(2.7 \%)$. This was attributed to favourable donor/acceptor energy level offsets, resulting in the highest $V_{\mathrm{OC}}$ values of around $1 \mathrm{~V}$, and improved $J_{\mathrm{SC}}$. Further optimisation of the device performance of this class of compounds as donor molecules in OPVs is underway.

\section{Experimental}

All experimental and instrumental details, including small molecule synthesis, electrochemistry and solar cell fabrication and characterisation are given in the ESI. $\dagger$

Table 4 Representative FET linear mobility values for holes $\left(\mathrm{h}^{+}\right)$and electrons $\left(\mathrm{e}^{-}\right)$

$\underline{\text { Charge carrier mobility } \mu\left(\mathrm{cm}^{2} \mathrm{~V}^{-1} \mathrm{~s}^{-1}\right)}$

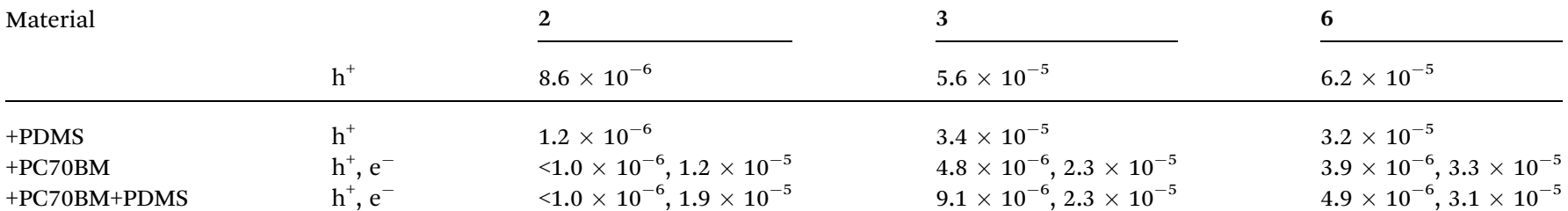




\section{Acknowledgements}

We thank the Cyprus Research Promotion foundation for funding the development of the Molecular Electronics and Photonics Research Unit at Cyprus University of Technology under Research Grant "NEA YPODOMH/STRATH/0308/06" and also for Grant no. "NEA YPODOMH/NEKYP/0308/02". Furthermore, we thank the A. G. Leventis Foundation for helping to establish the NMR facility at the University of Cyprus. This work was also supported by the Sonderforschungsbereich 953 "Synthetic Carbon Allotropes", the "Solar Technologies go Hybrid (SolTech)" and the China Scholarship Council (CSC).

\section{Notes and references}

1 United States Department of Energy, Basic Research Needs for Solar Energy Utilization, Report on the Basic Energy Sciences Workshop on Solar Energy Utilization April 18-21, 2005, Argonne National Laboratory, Lemont, IL, 2005.

2 Z. He, C. Zhong, S. Su, M. Xu, H. Wu and Y. Cao, Nat Photon., 2012, 6, 593.

3 S.-H. Liao, H.-J. Jhuo, Y.-S. Cheng and S.-A. Chen, Adv. Mater., 2013, 25, 4766.

4 J. You, C.-C. Chen, Z. Hong, K. Yoshimura, K. Ohya, R. Xu, S. Ye, J. Gao, G. Li and Y. Yang, Adv. Mater., 2013, 25, 3973.

5 J. You, L. Dou, K. Yoshimura, T. Kato, K. Ohya, T. Moriarty, K. Emery, C.-C. Chen, J. Gao, G. Li and Y. Yang, Nat. Commun., 2013, 4, 1446.

6 S. H. Park, A. Roy, S. Beaupré, S. Cho, N. Coates, J. S. Moon, D. Moses, M. Leclerc, K. Lee and A. J. Heeger, Nat Photon., 2009, 3, 297.

7 M. C. Scharber, M. Koppe, J. Gao, F. Cordella, M. A. Loi, P. Denk, M. Morana, H.-J. Egelhaaf, K. Forberich, G. Dennler, R. Gaudiana, D. Waller, Z. Zhu, X. Shi and C. J. Brabec, Adv. Mater., 2010, 22, 367.

8 H.-W. Lin, Y.-H. Chen, Z.-Y. Huang, C.-W. Chen, L.-Y. Lin, F. Lin and K.-T. Wong, Org. Electron., 2012, 13, 1722.

9 Y. Lin, Y. Li and X. Zhan, Chem. Soc. Rev., 2012, 41, 4245.

10 Y. Sun, G. C. Welch, W. L. Leong, C. J. Takacs, G. C. Bazan and A. J. Heeger, Nat. Mater., 2012, 11, 44.

11 T. S. van der Poll, J. A. Love, T.-Q. Nguyen and G. C. Bazan, Adv. Mater., 2012, 24, 3646.

12 Y. Liu, C.-C. Chen, Z. Hong, J. Gao, Y. Michael Yang, H. Zhou, L. Dou, G. Li and Y. Yang, Sci. Rep., 2013, 3, 3556.

13 J. Zhou, Y. Zuo, X. Wan, G. Long, Q. Zhang, W. Ni, Y. Liu, Z. Li, G. He, C. Li, B. Kan, M. Li and Y. Chen, J. Am. Chem. Soc., 2013, 135, 8484.

14 A. K. K. Kyaw, D. H. Wang, D. Wynands, J. Zhang, T.-Q. Nguyen, G. C. Bazan and A. J. Heeger, Nano Lett., 2013, 13, 3796.

15 Q. Zhang, B. Kan, F. Liu, G. Long, X. Wan, X. Chen, Y. Zuo, W. Ni, H. Zhang, M. Li, Z. Hu, F. Huang, Y. Cao, Z. Liang, M. Zhang, T. P. Russell and Y. Chen, Nat. Photon., 2015, 9, 35 .

16 W. L. Leong, G. C. Welch, L. G. Kaake, C. J. Takacs, Y. Sun, G. C. Bazan and A. J. Heeger, Chem. Sci., 2012, 3, 2103.
17 N. F. Montcada, B. Pelado, A. Viterisi, J. Albero, J. Coro, P. de la Cruz, F. Langa and E. Palomares, Org. Electron., 2013, 14, 2826.

18 A. Sharenko, C. M. Proctor, T. S. van der Poll, Z. B. Henson, T.-Q. Nguyen and G. C. Bazan, Adv. Mater., 2013, 25, 4403.

19 M. T. Dang, L. Hirsch and G. Wantz, Adv. Mater., 2011, 23, 3597.

20 Y. Lin, Z.-G. Zhang, H. Bai, Y. Li and X. Zhan, Chem. Commun., 2012, 48, 9655.

21 J. Min, Y. N. Luponosov, A. N. Solodukhin, N. Kausch-Busies, S. A. Ponomarenko, T. Ameri and C. J. Brabec, J. Mater. Chem. C, 2014, 2, 7614.

22 J. Min, Y. N. Luponosov, D. Baran, S. N. Chvalun, M. A. Shcherbina, A. V. Bakirov, P. V. Dmitryakov, S. M. Peregudova, N. Kausch-Busies, S. A. Ponomarenko, T. Ameri and C. J. Brabec, J. Mater. Chem. A, 2014, 2, 16135. 23 J. Min, Y. N. Luponosov, A. Gerl, M. S. Polinskaya, S. M. Peregudova, P. V. Dmitryakov, A. V. Bakirov, M. A. Shcherbina, S. N. Chvalun, S. Grigorian, N. KaushBusies, S. A. Ponomarenko, T. Ameri and C. J. Brabec, Adv. Energy Mater., 2014, 4, 1301234.

24 Y. Lin, L. Ma, Y. Li, Y. Liu, D. Zhu and X. Zhan, Adv. Energy Mater., 2013, 3, 1166.

25 H. Shang, H. Fan, Y. Liu, W. Hu, Y. Li and X. Zhan, Adv. Mater., 2011, 23, 1554.

26 S. P. Economopoulos, P. A. Koutentis, H. A. Ioannidou and S. A. Choulis, Electrochim. Acta, 2013, 107, 448.

27 T. Breining, A. R. Cimpoia, T. S. Mansour, N. Cammack, P. Hopewell and C. Ashman, Heterocycles, 1995, 41, 87.

28 G. Hamprecht, K. H. König and G. Stubenrauch, Angew. Chem., Int. Ed., 1981, 20, 151.

29 M. P. Cava, M. V. Lakshmikantham, R. Hoffmann and R. M. Williams, Tetrahedron, 2011, 67, 6771.

30 P. A. Koutentis, C. W. Rees, A. J. P. White and D. J. Williams, Chem. Commun., 2000, 303.

31 P. A. Koutentis and C. W. Rees, J. Chem. Soc., Perkin Trans. 1, 2000, 1081.

32 P. A. Koutentis and C. W. Rees, J. Chem. Soc., Perkin Trans. 1, 2000, 2601.

33 R. C. Haddon, M. L. Kaplan and J. H. Marshall, J. Am. Chem. Soc., 1978, 100, 1235.

34 T. Gómez, S. Macho, D. Miguel, A. G. Neo, T. Rodríguez and T. Torroba, Eur. J. Org. Chem., 2005, 2005, 5055.

35 S. Macho, D. Miguel, A. G. Neo, T. Rodríguez and T. Torroba, Chem. Commun., 2005, 334.

36 J. Geevers and W. P. Trompen, Recl. Trav. Chim. Pays-Bas, 1974, 93, 270.

37 H. A. Ioannidou, C. Kizas and P. A. Koutentis, Org. Lett., 2011, 13, 3466.

38 H. A. Ioannidou and P. A. Koutentis, Tetrahedron, 2012, 68, 7380 .

39 F. Silvestri, A. Marrocchi, M. Seri, C. Kim, T. J. Marks, A. Facchetti and A. Taticchi, J. Am. Chem. Soc., 2010, 132, 6108.

40 J. Y. Kim, K. Lee, N. E. Coates, D. Moses, T.-Q. Nguyen, M. Dante and A. J. Heeger, Science, 2007, 317, 222. 
41 A. Othonos, G. Itskos, M. Neophytou and S. A. Choulis, Appl. Phys. Lett., 2012, 100, 153303.

42 F. Hermerschmidt, P. Papagiorgis, A. Savva, C. Christodoulou, G. Itskos and S. A. Choulis, Sol. Energy Mater. Sol. Cells, 2014, 130, 474.

43 T. E. Kang, H.-H. Cho, C.-H. Cho, K.-H. Kim, H. Kang, M. Lee, S. Lee, B. Kim, C. Im and B. J. Kim, ACS Appl. Mater. Interfaces, 2013, 5, 861.

44 G. Dennler, M. C. Scharber and C. J. Brabec, Adv. Mater., 2009, 21, 1323.

45 M. C. Scharber and N. S. Sariciftci, Prog. Polym. Sci., 2013, 38, 1929.

46 M. C. Scharber, D. Mühlbacher, M. Koppe, P. Denk, C. Waldauf, A. J. Heeger and C. J. Brabec, Adv. Mater., 2006, 18, 789.

47 J. Peet, J. Y. Kim, N. E. Coates, W. L. Ma, D. Moses, A. J. Heeger and G. C. Bazan, Nat. Mater., 2007, 6, 497.
48 K. R. Graham, J. Mei, R. Stalder, J. W. Shim, H. Cheun, F. Steffy, F. So, B. Kippelen and J. R. Reynolds, ACS Appl. Mater. Interfaces, 2011, 3, 1210.

49 Q.-D. Dao, T. Hori, K. Fukumura, T. Masuda, T. Kamikado, A. Fujii, Y. Shimizu and M. Ozaki, Org. Electron., 2013, 14, 2628.

50 D. H. Kim, A. L. Ayzner, A. L. Appleton, K. Schmidt, J. Mei, M. F. Toney and Z. Bao, Chem. Mater., 2013, 25, 431.

51 M. Chandrasekharam, M. A. Reddy, K. Ganesh, G. D. Sharma, S. P. Singh and J. L. Rao, Org. Electron., 2014, 15, 2116.

52 J. Zhou, X. Wan, Y. Liu, Y. Zuo, Z. Li, G. He, G. Long, W. Ni, C. Li, X. Su and Y. Chen, J. Am. Chem. Soc., 2012, 134, 16345. 53 S. Wakim, B.-R. Aich, Y. Tao and M. Leclerc, Polym. Rev., 2008, 48, 432.

54 H.-C. Liao, C.-C. Ho, C.-Y. Chang, M.-H. Jao, S. B. Darling and W.-F. Su, Mater. Today, 2013, 16, 326. 